\title{
El tratamiento audiovisual de los sucesos en la Web. Un caso de estudio sobre el tratamiento de las noticias de Marta del Castillo en Rtve.es y Telecinco.es
}

\section{The Audiovisual Treatment of crime reports on the web. A study case about the treatment of Marta del Castillo's case in Rtve.es and Telecinco.es}

Eva Herrero Curiel. Universidad Carlos III de Madrid

Recibido: 12-X-2011 - Aceptado: 24-VII-2013

Resumen:

Internet ha generado grandes cambios en el entorno periodístico, pero géneros clásicos como el suceso siguen estando presentes en las agendas de los medios, sobre todo de las televisiones que han encontrado en la Red nuevas formas de exhibir sus contenidos. En esta investigación, y a través del caso particular de Marta del Castillo, se ha analizado el tratamiento audiovisual que dicha noticia recibió en las webs de Rtve.es y Telecinco.es con la finalidad de encontrar diferencias, o semejanzas, en función de la naturaleza pública o privada de estos medios. Partiendo de un análisis de contenido de las piezas audiovisuales durante la semana que más cobertura mediática recibió el caso, se han medido diferentes categorías que reflejan que Rtve.es aportó una visión más informativa que Telecinco.es cuya tendencia refleja un carácter más afectivo y sensacionalista.

Palabras clave:

Internet, información audiovisual, televisión pública, televisión privada, Rtve.es, Telecinco.es.

Abstract

Internet has generated big changes in the journalistic environment, but classical genres like crime report are still present in the media agenda, especially in channels that have found in the Internet new forms of exhibiting their contents. In the present paper, the audiovisual treatment that these news have received has been analyzed through Marta del Castillo's case in both Rtve.es and Telecinco.es. The purpose was to find differences and similarities between public (Rtve.es) and private media (Telecinco.es). A content analysis of the week with the highest rate of coverage for the case revealed that Rtve.es provides with a more informative view, as opposed to Telecinco.es, which tends to be more affective and sensationalist.

Keywords:

Internet, audiovisual information, public television, private television, Rtve.es, Telecinco.es 


\section{Introducción}

Las nuevas tecnologías y la convergencia tecnológica entre los diferentes medios de comunicación han hecho posible que en la actualidad hablemos del germen del tercer modelo televisivo que, como definía en 2004 Mariano Cebrián Herrero, no es más que "la plena convergencia de la televisión a Internet" (2004: 215). Hoy en día, cualquier usuario puede elegir de qué manera ver la televisión. Puede, por ejemplo, ver los informativos en directo a través del televisor, o bien, acceder a Internet y verlos en diferido eligiendo además cualquier edición de los mismos, o incluso, determinadas piezas informativas. Estamos en la era de la televisión a la carta.

Los canales de televisión se han incorporado, al igual que lo han hecho las emisoras de radio o los periódicos, a la web. Si la televisión recoge, por una parte, el relato de imagen fija, fotografía y cine; y por otra, la aportación del sonido radiofónico, con la incorporación a Internet han aumentado las prestaciones propias de una pieza audiovisual, ya que adicionalmente se ofrece un texto que acompaña a la pieza, la posibilidad de interacción por parte del usuario y por supuesto, la libre elección de decidir en qué momento visionar una pieza y desde donde hacerlo; superando así cualquier barrera temporal y espacial.

Las cadenas de televisión se han instalado poco a poco en la Web, a finales de los 90 presentaban un notable retraso respecto a otros medios como la prensa o la radio que parecían ir más allá de las desventajas técnicas del medio por el escaso ancho de banda disponible (Bustamante, 2002:253). Sin embargo, la situación ha cambiado y la incorporación de la televisión a Internet ha mejorado notablemente, situándose las sites de las principales cadenas de televisión españolas entre las 10 webs con más visitantes únicos (AIMC, 2012: 63), los responsables de las cadenas de televisión han visto en la World Wide Web una gran ventana de posibilidades para distribuir sus contenidos.

Las diferentes características inherentes a Internet (multimedialidad, hipertextualidad, interactividad, ubicuidad, etc.) han hecho posible que las televisiones puedan adaptar su mensaje audiovisual al entorno digital, donde la información se consume de una forma más rápida y la experiencia del usuario es más activa en comparación a otros medios más tradicionales. Los vídeos que se cuelgan en Internet están condicionados por las aportaciones globales de la Red (Cebrián Herreros, 2004: 265), es necesario que las televisiones adapten sus versiones a internet (Tourinho, 2009:252). Así, por ejemplo, las piezas informativas que el usuario se encuentra en la web de una cadena de televisión serán más breves que las que se puedan ver en el medio tradicional; esto es necesario para poder adaptarse a las rigurosas características técnicas del ciberespacio. 


\section{Marco teórico}

\subsection{La televisión ante Internet}

La transposición de la televisión a Internet hace que ésta pueda traspasar "una programación completa, programas y fragmentos de programas"(Díaz Arias, 2009: 65), superando así la limitación lineal y unidireccional de la televisión tradicional. Estamos hablando de lo que se conoce como televisión a la carta y que permite al usuario acceder de forma asincrónica a diferentes programas o secciones de programas. La televisión a la carta está siendo muy explotada en el área de la ficción televisiva, así algunas cadenas llevan a cabo acciones de promoción de series adelantando por Internet los primeros capítulos o poniendo a disposición del usuario los episodios completos en la web, para que éste los pueda visionar en cualquier momento y desde cualquier dispositivo. No olvidemos que la aparición de tabletas y smartphones están potenciando cada vez más esta forma de ver la televisión.

No todas las cadenas de televisión están plenamente integradas en Internet. Existen en la actualidad más de 800 canales de televisión que emiten su programación a través de la Red (Ruano, 2008:56), sin embargo muchas de ellas ofrecen tan solo una versión modificada de contenidos que ya existen, aunque el panorama ha mejorado si tenemos en cuenta sus comienzos: "las principales cadenas de televisión concibieron la posibilidad de subir a la web su programación ordinaria, por considerar a la televisión en Internet como una simple extensión de la televisión convencional, sin entender que la programación debía ser distinta, ya que no encajaba con el tipo de persona que navegaba por la red” (Rodríguez, 2010). El futuro inmediato nos lleva a entender la comunicación plenamente integrada, algo que será posible gracias a la "convergencia tecnológica" (Jenkins, 2006), un fenómeno que nace de la capacidad del nuevo medio para integrar los diferentes formatos existentes dentro de la comunicación de masas.

Las diferentes websites de las emisoras televisivas presentan múltiples áreas de interés para el usuario. De esta manera podemos encontrar secciones de entretenimiento (series, programas), informativos, concursos, opinión... Nuestro trabajo se enmarca en el área de los informativos que son los que se encargan, a través de un equipo específico para la parte on line, de generar la información en tiempo real y actualizada; de esta manera los vídeos a los que la audiencia puede acceder están en constante actualización.

Esta actualización, característica propia del nuevo medio, hace que en ocasiones las piezas audiovisuales que vemos en un determinado momento no se correspondan con el momento real en el que lo vimos por televisión. A nivel de investigación académica, esta es una variable extraña que hay que tener en cuenta en los resultados. La pieza audiovisual que se ve por televisión se puede grabar en ese momento y analizarla sin que haya sufrido ninguna modificación, sin embargo en la web se pueden rescatar vídeos que, aunque datados en una fecha determinada, pueden estar modificados, re-editados o incluso montados con nuevas imágenes y nuevos datos. 


\subsection{La convergencia de tecnologías}

Internet ha generado en el ámbito periodístico un nuevo modelo de comunicación que hace que medios tradicionales como la televisión, la radio o los periódicos tengan en cuenta otros canales como Internet para poder trasmitir su mensaje. La naturaleza multimedia de la Red permite que una misma noticia sea ofrecida en diferentes formatos. Además del canal, otro de los elementos comunicativos, posiblemente el más importante para las empresas, que ha experimentado una profunda trasformación, es el del receptor.

Si antes los servicios informativos de una televisión editaban una pieza informativa destinada a un público que no tenía posibilidad de modificar nada, ahora se enfrentan a un consumidor que como usuario de Internet puede difundir el mensaje, colgando el vídeo en su blog o en su red social, incluso interpretarlo propagando a los demás usuarios un nuevo mensaje que nada tenía que ver con el anterior. En definitiva, estamos ante un usuario que puede reconvertirse en emisor; o lo que como muchos autores han acuñado, estamos ante el User Generated Content (García-De-Torres, 2010).

La aparición de Internet ha modificado el canal o el medio a través del cual se trasmitían los mensajes. Este nuevo soporte ha dado lugar a lo que se conoce como convergencia tecnológica, ya que la Red permite que en un mismo medio convivan diferentes formatos por los cuales se difunde el mensaje. ¿Cómo se han adaptado las televisiones a este fenómeno? A través de la narración transmediática.

"Una historia transmediática desarrollada a través de múltiples plataformas mediáticas... hace una contribución específica y valiosa a la totalidad" (Jenkins, 2006: 101). La historia puede presentarse en televisión en forma de reportaje largo de dos o tres minutos y cuando se decide narrar esa historia a través de la web se monta con una duración de un minuto y medio y con posibilidad, además, de navegar por vídeos e informaciones anteriores relacionadas con el caso.

A través de la narración transmediática, el medio de comunicación crea un mensaje y luego lo va adaptando, o dando forma, en función del formato en el que decida transmitirlo; no será lo mismo el mensaje en televisión, que a través de un vídeo colgado en una web, que da la posibilidad al usuario de comentar el mensaje o hacerlo protagonista a través de diferentes aplicaciones.

\subsection{La diferencia entre televisión pública y privada}

A la hora de comparar el tratamiento audiovisual en un medio de comunicación de naturaleza estatal, como es Rtve.es y un medio privado como es Telecinco.es se hace necesario establecer ciertas diferencias entre un medio y otro en relación a su naturaleza pública o privada, ya que este hecho lleva a aparejado una serie de connotaciones y significados que juegan un importante papel dentro de la sociedad de la información. 
Desde algunos sectores se ha creído que la televisión pública debía tener una intención educativa, no se trata tanto de esta finalidad, sino más bien de que la televisión pública, y en nuestro caso la web de una televisión pública, debe ofrecer aquello que no hacen las televisiones privadas. "El contenido formativo no está únicamente en textos que se asumen como tales" (Mazziotti, 2005:192), sino que se puede encontrar en cualquier otro contenido de diferente naturaleza. Algo que se puede encontrar en las imágenes utilizadas para el montaje, en los testimonios y en la propia narración que hace el periodista sobre las imágenes que presenta.

Hasta ahora, todo el mundo sabe que la televisión pública, en el caso en concreto que estamos estudiando Rtve.es, continúa manteniendo su objetivo de servicio público con independencia de otras presiones y la televisión privada abre la vía de la competitividad para ofrecer productos diferenciados y atractivos para los destinatarios. Esto lleva a establecer una primera diferencia que afectará de lleno a las noticias que dan unas u otras, mientras que en la televisión pública se tiende a profundizar más en los hechos y a contextualizar (Cebrián Herreros, 2004), en la televisión privada se da más importancia a los enfoque comerciales, aquellos que, aunque no profundicen demasiado en los acontecimientos, si reúnan frente al televisor un gran número de telespectadores. Se trata de una primera aproximación bastante estereotipada, ya que la televisión pública también necesita ser vista por un gran número de personas, de lo que sería la gran diferencia en el tratamiento informativo desde una emisora pública, y además estatal, frente a una privada.

Es verdad que en los últimos años se han llevado a cabo diversas reformas que pretenden transformar el modelo de televisión pública en España para equipararla al resto de Europa y resaltar así su garante para la democracia, la cohesión social, la diversidad cultural, el pluralismo y la información independiente, cuya mayor rentabilidad sea la social. Pero todavía hoy, se está discutiendo si la televisión pública en España está cumpliendo con esta función o si, por el contrario, como muestran algunos aspectos de su programación, parece una más dentro del resto de oferta televisiva de la que disponemos.

\subsection{Una aproximación al suceso en televisión}

La Real Academia de Lengua Española define el término suceso como una "cosa que sucede, especialmente cuando es de alguna importancia”. Hoy en día, con la aparición de Internet, las noticias de suceso ya no son solo el tema clave de la televisión, sino que gracias a la Red y sus múltiples posibilidades, el género del suceso ha pasado a formar parte de la agenda de los medios digitales, en ocasiones configurando una sección única. Roland Barthes en 1962 definía el suceso como una estructura cerrada que tiene circunstancias, causas, pasado, desenlace; sin duración y sin contexto, que cumple una función de preservación en el seno de la sociedad contemporánea de lo racional y de lo irracional. Y es que las noticias sobre sucesos son, en la actualidad, relatos cortos de un fácil consumo por parte del usuario, que no se siente responsable ante ellos y los ve como un hecho o un acontecimiento lejano a su vida; por otro lado, un género idóneo para el rápido consumo que fomenta la red. 
Los informativos de las principales cadenas de televisión persiguen lo que hacen el resto de programas: ser líderes de audiencia en su franja horaria. Es quizá por este motivo por el que la crónica del suceso se convierte en fundamental en estos medios.

En el suceso la realidad ya está ahí, el acontecimiento ha sucedido, de lo que se encarga la televisión es de narrar esa realidad; ahora bien, desde el momento en el que las imágenes captadas por las cámaras pasan por un proceso de edición, montaje y post producción, esa realidad que se narra puede quedar modificada y por tanto alterada. "La televisión que pretende ser un instrumento que refleja la realidad, acaba convirtiéndose en instrumento que crea una realidad" (Bordieu, 1996: 20), de forma que la realidad que percibe el espectador de una cadena de televisión acerca de un determinado suceso puede ser muy diferente de la de quien lo recibe por otro canal de televisión. Se podría decir que cada televisión puede crear una realidad, a veces más dura que otra, en función de los planos, la edición o la post producción que lleve la pieza final.

El tema de los sucesos en televisión tiene gran trascendencia si tenemos en cuenta los datos de un estudio sobre la sección de sucesos en los informativos de las cuatro principales televisiones privadas en España realizado por la Universidad Complutense de Madrid que demuestra que en 2009, los 24 informativos analizados de Antena3 TVy Telecinco suman 328 minutos de información de sucesos (Mayoral, 2009), más del triple que en 2000, además con un aumento notable de imágenes impactantes y testimonios irrelevantes.

En este trabajo se pretende examinar, además, el encuadre noticioso desde el que se han construido las diferentes piezas audiovisuales. En el año 2000 las autoras Holli Semetko y Patti Valkenburg determinaron la existencia de cinco encuadres que permiten desarrollar de una manera efectiva el análisis de los contenidos de los medios: la atribución de responsabilidad, el conflicto entre individuos, grupos o instituciones, el interés humano con el que se "dramatiza" o "emociona" la información, la moralidad enmarcada en un contexto de principios religiosos o prescripciones morales y las consecuencias económicas, presentando el asunto en términos de los efectos económicos a los que tendrá que hacer frente.

\section{Diseño de la investigación}

\subsection{Objeto de estudio}

Descripción del tratamiento informativo que recibieron las piezas audiovisuales sobre Marta del Castillo alojadas en la web de Rtve.esY Telecinco.es durante la semana del 14 de febrero hasta el 21 de febrero de 2009. 


\subsection{Preguntas de Investigación}

- $\quad$ ¿Hubo diferencias en el tratamiento de los vídeos sobre Marta del Castillo en Rtve.es y Telecinco.es?

- $\quad$ ¿En qué web de informativos se alojaron más vídeos durante el periodo analizado?

- $\quad$ ¿Fueron las piezas audiovisuales sobre Marta del Castillo más informativas en Rtve.es?

- $\quad$ ¿Los vídeos alojados en Telecinco.es tenían connotaciones afectivas en mayor medida que Rtve.es?

\subsection{Objetivos}

- $\quad$ Descripción formal y de contenido de los vídeos analizados sobre Marta del Castillo.

- $\quad$ Análisis del tratamiento informativo que presentan las piezas audiovisuales

- $\quad$ Análisis de las diferentes categorías observadas en los vídeos.

- $\quad$ Establecimiento de diferencias entre los vídeos alojados en Rtve.es y en Telecinco.es

\subsection{Metodología}

La estrategia de investigación se basa en un caso de estudio ateórico ${ }^{1}$ (Marta del Castillo) en el que hemos llevado a cabo un análisis exploratorio - descriptivo a través de técnicas de carácter cualitativo y cuantitativo. Se ha realizado un análisis de contenido a través de diferentes categorías, definidas en los siguientes epígrafes, el enfoque metodológico es hipotético-inductivo ya que a partir de los datos observados y analizados extraeremos una serie de generalizaciones para este caso particular que puedan servir de referencia para casos similares.

\subsection{Unidad de análisis}

Las piezas audiovisuales sobre el caso de Marta del Castillo alojadas en las sites de Rtve.es y Telecinco.es, respectivamente, durante la semana del 14 de febrero hasta el 21 de febrero de 2009. El periodo elegido responde a la gran atención mediática generada por la detención de los implicados y que coincide con el periodo analizado por el Servicio de Análisis del Consejo Audiovisual de Andalucía para realizar un Informe general sobre el tratamiento informativo del caso Marta del Castillo.

Por su parte, la selección de los dos medios elegidos para este estudio responde a un criterio de audiencia y de la naturaleza, estatal o privada, del medio analizado. Así, Rtve.es se ha elegido por su carácter estatal y público; y Telecinco.es se ha

1 "Se trata de un tipo de caso de estudio íntegramente descriptivo, no hay un interés de realizar generalizaciones ni de formular hipótesis a posteriori” (Kazez, 2009:5). 
elegido porque se trata de la web de una televisión comercial con más visitas durante el mes analizado, exactamente 1.532 visitantes únicos (EGM, 2009).

\subsection{Muestra}

Todos los vídeos sobre Marta del Castillo alojados en las webs de informativos de Rtve.es y Telecinco.es durante el periodo analizado, que comprende el día en el que Miguel Carcaño confiesa el asesinato de la joven (14 de febrero) hasta la manifestación convocada por la familia y amigos de Marta en Madrid para exigir la cadena perpetua (21 de febrero). El número de vídeos analizados ha sido 31, el visionado total ha sido de 67 minutos.

\subsection{Categorías de análisis}

Datos de identificación básicos: Para cada unidad de análisis se identificó la fecha y hora de publicación, la web en la que aparecía.

El encuadre de las noticias: Para esta categoría se ha utilizado una versión, adaptada a nuestro objeto de estudio, de la escala original que elaboraron las autoras Holli Semetko y Patti Valkenburg en el año 2000 y que también utilizó Igartua en un estudio de 2004 . En este trabajo se han tratado de evaluar cinco encuadres noticiosos, la manera de codificarlos ha sido la misma que en la escala original, es decir de forma dicotómica, con 1 para aquellos encuadres que estuvieran presentes y con un 0 para aquellos que no aparecieran en las piezas audiovisuales analizadas.

Atribución de responsabilidad, se considera que este encuadre noticioso está presente en la pieza analizada, si en las informaciones que se trasmiten en la pieza audiovisual, a través de la voz en off la responsabilidad de solucionar el suceso recae sobre un individuo, un gobierno o una institución.

Conflicto, este encuadre noticioso se da cuando en las informaciones analizadas se presentan diferentes posturas frente al mismo tema, reproches entre partidos políticos con respecto al tema o reproches entre individuos e instituciones; así como desacuerdos entre políticos, individuos o instituciones.

Interés humano, aparece cuando se pretende dramatizar la información. Los rasgos característicos que determinan la presencia de este aspecto son la aparición en escena de una persona en concreto, cuando se adentran en la vida privada de los actores o protagonistas de la noticia, cuando se presenta información visual que en el espectador pueda provocar simpatía o agravio (ejemplo la mirada desafiante del asesino cuando entra en comisaría) o las declaraciones de personas implicadas en el caso.

Moralidad, cuando el relato analizado contiene algún tipo de mensaje moral; este se puede identificar cuando aparecen prescripciones sociales específicas de cómo se debería actuar. 
Consecuencias económicas, cuando se hace referencia a los costes económicos de determinadas situaciones o a las consecuencias económicas de determinadas acciones con relación al tema o suceso.

Los personajes: Dentro de cada pieza informativa se identificaron los personajes de los implicados en el caso que aparecían en las imágenes, de forma que ante su presencia se codificaba como 1.

Marta del Castillo: cualquier imagen o fotografía de ella.

Los padres de Marta: Antonio del Castillo y Eva Casanueva.

El tío de Marta del Castillo: Se trata de portavoz de la familia.

Miguel Carcaño: ex novio de Marta del Castillo de 20 años de edad, asesino confeso de la joven y uno de los principales sospechosos del caso.

El Cuco: Francisco G.M, uno de los implicados y menor de edad, está acusado de participar en la desaparición del cuerpo de Marta del Castillo. Se encuentra en un piso tutelado.

El hermano de Miguel: Francisco Javier Delgado.

Samuel Benítez: amigo de Marta del Castillo y de Miguel Carcaño. Se le acusa de encubrimiento y profanación del cadáver.

Ex novia de Miguel Carcaño: Se trata de otra menor de edad implicada en el caso y a la que se le acusará de encubrimiento.

Amigos de Marta: En esta categoría incluimos a cualquiera de los conocidos de Marta del Castillo u otros familiares que puedan aparecer en las imágenes y que no estén directamente implicados en el caso como los anteriores.

Otros: En esta categoría se han contabilizado a aquellos personajes no citados anteriormente y que aparezcan en los vídeos. Por ejemplo, este sería el caso de los abuelos de Marta del Castillo o de cualquier responsable de la búsqueda e investigación de lo ocurrido (policía, investigadores...).

Desarrollo de las noticias, en cada pieza informativa existen varias opciones para presentar el relato:

Colas. Su duración no supera el minuto y medio, se trata del relato de imágenes que incorporan la voz en off. Las imágenes se editan siguiendo el orden que se quiera, pero eliminando el sonido ambiente y con una voz en off que se incorpora para ir danto datos o describiendo, incluso elementos que no se pueden ver en las imágenes.

Directo. En esta categoría contemplamos aquellos directos que se han colgado en la web, donde aparece el reportero en el lugar de los hechos, teniendo en cuenta que no es un directo real ya que se ha colgado en Internet después de haber sido emitido. El reportero acude al lugar de los hechos y conecta en directo con el informativo. La utilización de este formato da mayor actualidad al relato, lo dota de mayor importancia y despierta en el espectador un mayor interés informativo. 
Reportaje. La duración suele ser mayor que las colas, puede llegar incluso a los diez minutos y con este género se intenta contextualizar de una forma más profunda al acontecimiento, además se da la posibilidad al espectador de conocer otros puntos de vista y ponerlo en antecedentes. Se trata del género estrella de la televisión.

Tipos de plano: La tipología de los planos representa la materia prima que ha de estar al servicio de un relato, un guion: es decir, de una secuencia articulada de planos con eficacia comunicativa (guion) que se llama noticia. Para este trabajo la clasificación de los planos se ha hecho según el tamaño de la imagen.

Plano General, con este plano permitimos al espectador que tenga una amplia visión del entorno o escenario de la acción con personajes en contexto tamaño medio.

Primer Plano, se trata de un plano muy intimista y que permite una penetración emocional de la persona y detalle del objeto. Se trata de una imagen más afectiva que informativa.

Plano Detalle, la información nos emplaza visualmente ante un elemento que debe ser visto con la máxima proximidad: un texto, un objeto, un detalle corporal, etc., porque forma parte imprescindible de la información y las claves del relato.

Primerísimo Primer Plano (PPP), se trata de un primer plano muy cerrado y que muestra detalladamente una parte del personaje. Es muy poco utilizado ya que, si no está muy justificado, puede llegar a ser aberrante para el personaje al que se graba.

Plano Americano, es muy funcional. Permite proximidad y un cierto relato de la relación que los personajes establecen entre sí. El estándar limita la toma hacia no mucho más debajo de las rodillas.

Presencia del periodista: En esta categoría la recogida de la información se ha planteado de forma dicotómica con un 1 cada vez que salía ante la cámara un periodista y con un 0 si en el lugar de los hechos no estaba el reportero. Esta categoría está estrechamente relacionada con la del formato audiovisual, ya que en los directos la presencia del periodista suele ser habitual.

Los espacios vacíos: con esta categoría se intenta ver si los espacios vacíos que aparecen en el relato audiovisual han sido utilizados como un recurso retórico o técnico. Para construir esta categoría se ha recurrido a un artículo de Puyal Sanz publicado en 2008 en el que se habla de cómo el periodismo audiovisual puede emplear ciertos efectos vacíos con una voluntad expresiva.

Retórico: se subraya la importancia del hecho, precisamente poniendo en evidencia una ausencia. La carga informativa no recae sobre aquellos que captaron las cámaras en el momento del hecho, sino en los consecuentes de este hecho. Se trata de la tendencia a sobredimensionar la realidad, convirtiendo los hechos de escasa trascendencia informativa en acontecimientos mediáticos. Daniel Boorstin los llamará "pseudo-eventos". Con esto la información televisiva no hace sino otorgar a estos espacios vacíos un valor simbólico o mítico que a veces no está del todo justificado. 
Técnico: se aprovecha ciertos espacios vacíos como imágenes de recurso para montar la pieza, es decir, no existe una intención retórica sino que se utiliza esa imagen igual que hubiera podido utilizar cualquier otra para llenar o completar la pieza informativa.

Tipo de contenido: en esta categoría de análisis se pretende estudiar si la construcción audiovisual de la noticia era de naturaleza informativa, ofreciendo datos, diferentes puntos de vista, o bien si por el contrario se trataba de una construcción más afectiva dando importancia a detalles sensacionalistas o apelando a testimonios subjetivos, como podían ser personas llorando, manifestándose o incluyendo fotos privadas de los menores que pudieran violar sus derechos.

\section{Resultados}

\section{1. ¿Qué cadena alojó más vídeos en su web de informativos?}

Durante la semana analizada, la web de Rtve.es alojó más vídeos sobre la noticia de Marta del Castillo en su sección de informativos que Telecinco.es. En el caso de la cadena pública se colgaron 21 vídeos en esos 8 días frente a los 10 que se colgaron en la cadena privada. Además, se ha observado una mayor actualización en los vídeos de Rtve.es ya que estos coincidían con las diferentes ediciones de informativos de la cadena pública. En el caso de Telecinco.es se han encontrado menos vídeos en la sección de informativos, sin embargo algunos de sus programas como (El programa de Ana Rosa o La Noria) sí colgaban en la web algunas piezas y especiales sobre el caso, aunque estos no han sido objeto de este trabajo al no encontrarse en el área puro de informativos.

Tabla 1. Frecuencia de vídeos

\section{Vídeos}

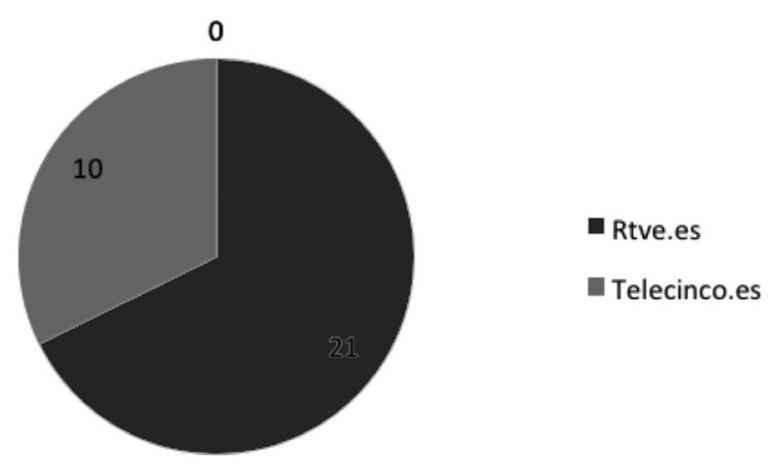

Fuente: elaboración propia. 


\section{2. ¿A qué aspectos se da más relevancia a la hora de trasmitir la noticia?}

La mayor parte de los vídeos analizados, tanto de Rtve.es como de Telecinco.es, están encuadrados desde el punto de vista de la "atribución de la responsabilidad", uno de los primeros encuadres a los que las autoras Semetko y Valkemburg hacían referencia. En el caso de Rtve.es (tabla 2) el 62\% de los vídeos visionados hacían referencia explícita al responsable de lo sucedido con la desaparición de Marta del Castillo, se trata de un dato significativo si se tiene en cuenta que el otro encuadre noticioso que con mayor frecuencia aparecía en los vídeos era el del conflicto, con tan solo un 24\%; y por último, y de forma casi anecdótica, la perspectiva del interés humano solo se ha visto en un $14 \%$ dentro de la web de Rtve.es.

Tabla 2. Encuadres de la noticia

- Atribución Conflicto Interés humano

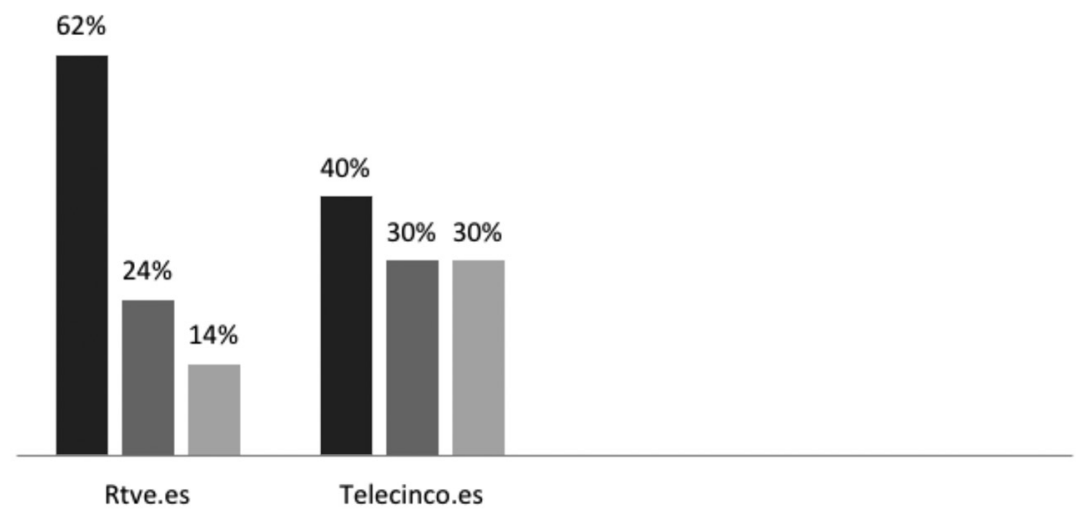

Fuente: elaboración propia.

El resto de encuadres noticiosos, y quizá los más subjetivos (moralidad o consecuencias económicas), no han aparecido en los vídeos de Rtve.es, lo que refleja un contenido audiovisual de carácter informativo y objetivo en relación al momento temporal del caso: cuando todavía no se ha encontrado el cadáver, se está buscando e investigando a los presuntos culpables.

En cuanto a los resultados obtenidos del análisis de los vídeos de Telecinco.es (tabla 2), se puede apreciar una diferencia de enfoques de la noticia. En el caso de Telecinco sólo un 40\% de las piezas analizadas se corresponden al encuadre de atribución de la responsabilidad y el restante $60 \%$ se divide en partes iguales entre un enfoque de conflicto y el encuadre centrado en el interés humano. Aunque no se trata de unos resultados significativos, es posible que ante un mayor periodo de análisis temporal sí que se hubiera encontrado una diferencia significativa que nos permitiera concluir que los 
encuadres noticiosos analizados en las piezas audiovisuales colgadas en Telecinco.es sobre Marta del Castillo son más subjetivos que los de Rtve.es.

\section{3. ¿Cuáles son los personajes que más aparecen en la historia?}

Una de las partes esenciales de cualquier narración, o historia audiovisual que se precie, son los personajes que aparecen en ella; pero en este caso, donde la noticia que se narra está relacionada con temas de gran calado social como son la violencia machista o los menores, se hace más necesario ver a quién dan más protagonismo los medios de comunicación. Algunos manuales de buenas prácticas sobre cómo informar de violencia advierten del peligro que tiene dar un mayor protagonismo a los culpables que a las víctimas, ya que podemos convertir a los culpables en estrellas mediáticas. "Hay casos en que la propia prensa hace de un agresor una estrella porque su acto lo consideran de un interés comercial extraordinario" (Díaz Fernández, 2003:82). La historia noticiosa se desarrollará en sucesivas y fragmentadas fases informativas, por pequeños capítulos o episodios.

En el caso analizado en este trabajo se puede observar como en ambas cadenas de televisión los personajes que más aparecen son el de Miguel Carcaño, asesino confeso, y la víctima, Marta del Castillo; o personas de su entorno más cercano (amigos, familiares). Hay que tener en cuenta que en Rtve.es, donde la frecuencia de apariciones de Miguel Carcaño es de un 57\%, ha habido un número mayor de piezas audiovisuales analizadas, por lo tanto la frecuencia es más alta. Por su parte, en la web de Telecinco.es la frecuencia de aparición de Marta del Castillo así como la de Miguel Carcaño y sus cómplices es la misma: un $30 \%$ (tabla 3 ).

El hecho de que finalmente los personajes que más aparecen en los medios de comunicación se encuentren en el entorno del asesino y no de la víctima, hace que la audiencia termine familiarizándose demasiado con los culpables hasta el punto de que en muchos casos se intente entender o justificar su actuación. Así, en los días en los que Miguel Carcaño acudía a los juzgados se generaron grupos de fans que mandaban cartas al supuesto asesino mostrándole su apoyo y consideración. 
Tabla 3. Personajes

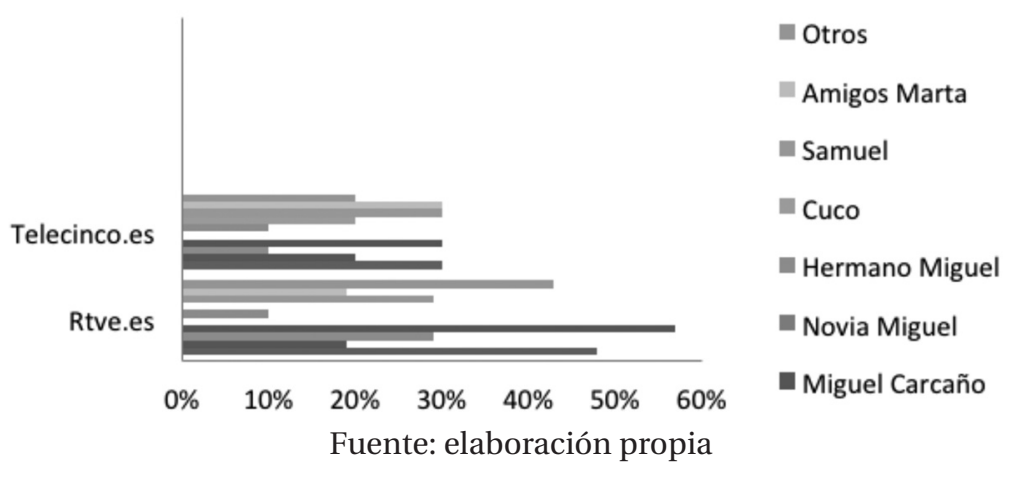

\section{4. ¿Cuáles son los formatos preferidos para contar la historia?}

En esta categoría hemos encontrado resultados semejantes en ambas webs de televisión (tabla 5). En el 48\% de los vídeos analizados en Rtve.es y en el 60\% de los vídeos analizados en Telecinco.es el formato preferido para narrar la noticia ha sido el directo, entendiendo que en el caso de la web es un directo diferido ya que primero se ha emitido a través de la televisión. En el caso de Telecinco.es se ha visto que un 40\% de los vídeos sobre Marta del Castillo eran reportajes, un género muy apropiado para una noticia de esta naturaleza ya que permite al espectador situarse y ponerse en antecedentes. El hecho de que haya habido más reportajes en Telecinco permite que también se haya dado más protagonismo a otros personajes.

En el caso de Rtve.es hay un cierto equilibrio en la frecuencia de utilización de los diferentes formatos, caso que no vemos en la cadena privada donde la utilización de colas para el montaje de vídeos es inexistente.

Tabla 4. Formatos audiovisuales Rtve.es y Telecinco.es

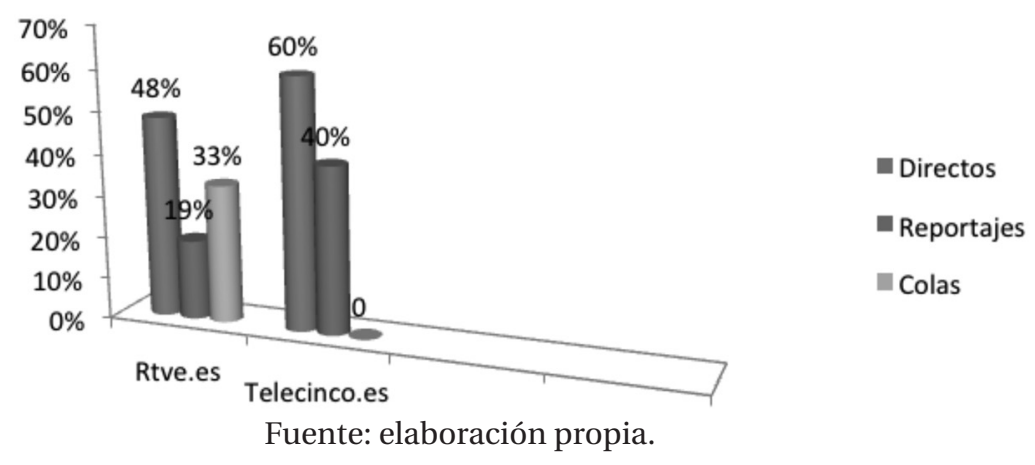




\section{5. ¿Cuáles son los planos preferidos para el montaje de las piezas audiovisuales?}

En ambas webs los planos generales y los planos americanos son los que más abundan en relación al resto de planos (tabla 5). Por tanto, la elección a la hora del montar los vídeos pasa por la objetividad y contextualización para ayudar al espectador a tomar perspectiva. Los primeros planos también son el tercer tipo de montaje más utilizado y esto se debe probablemente a la carga afectiva de la noticia y a la temática de interés humano a la que responde. Los planos detalle y los primerísimos primeros planos apenas aparecen en los montajes.

Tabla 5. Frecuencia de planos en Rtve.es y Telecinco.es

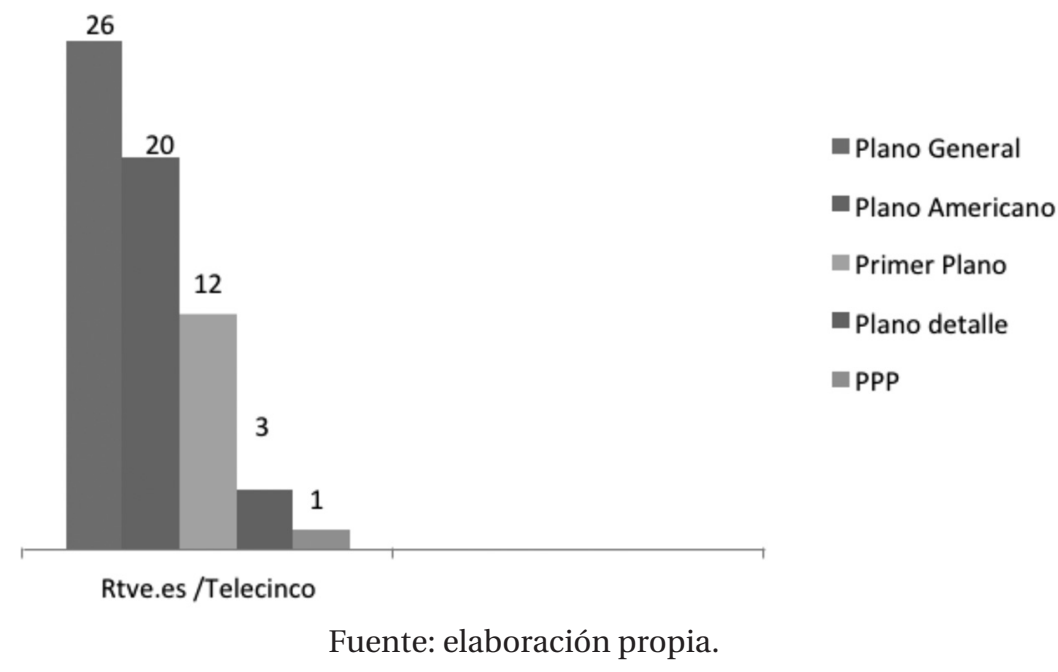

\section{6. ¿Aparece el periodista ante las cámaras?}

Aunque la aparición del periodista en los vídeos alojados en la web no suponen una conexión en directo real, porque hemos visto antes que en las web de las televisiones los directos se cuelgan a posteriori de la emisión, lo cierto es que al haber bastantes directos, la frecuencia en la presencia del periodista se encuentra casi en la mitad de los vídeos analizados en el caso de Rtve.es y en la mitad de los alojados en la página de Telecinco.es. 
Tabla 6. Presencia de los periodistas en Rtve.es y Telecinco.es
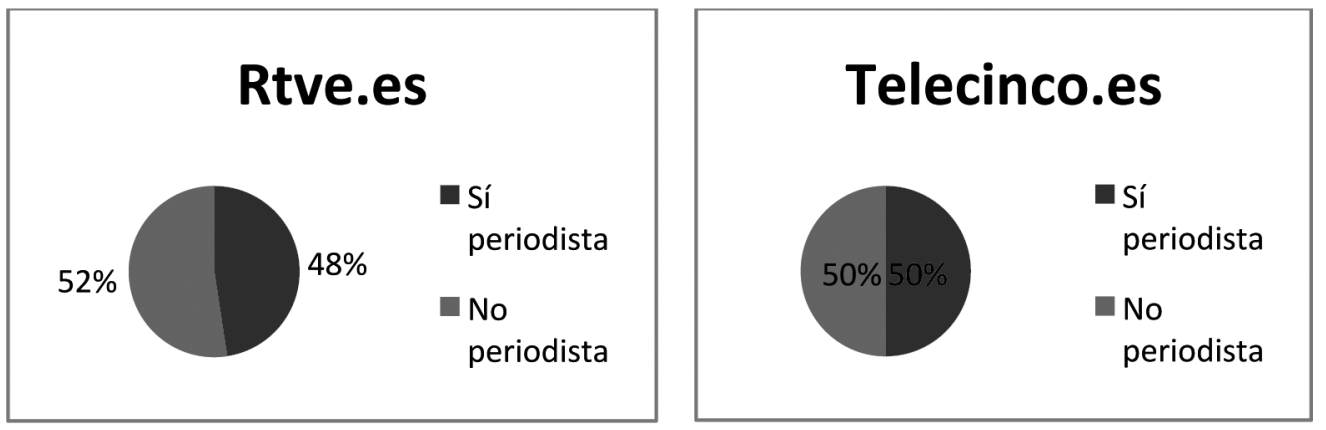

Fuente: elaboración propia.

\section{7 ¿Se utilizan los espacios vacíos con una finalidad técnica o retórica?}

Los resultados obtenidos nos muestran que los usos que se hacen de los espacios vacíos en las piezas audiovisuales de Marta del Castillo tienen una finalidad técnica. En la mayoría de los casos se utilizan como planos recursos para cubrir el montaje. Se puede concluir, por tanto, que solo un $10 \%$ en Rtve.es y un $20 \%$ en Telecinco.es de los vídeos analizados (tabla

7) la finalidad de los espacios vacíos era estética o retórica.

Tabla 7. Vacíos técnicos o retóricos en Rtve.es y Telecinco.es

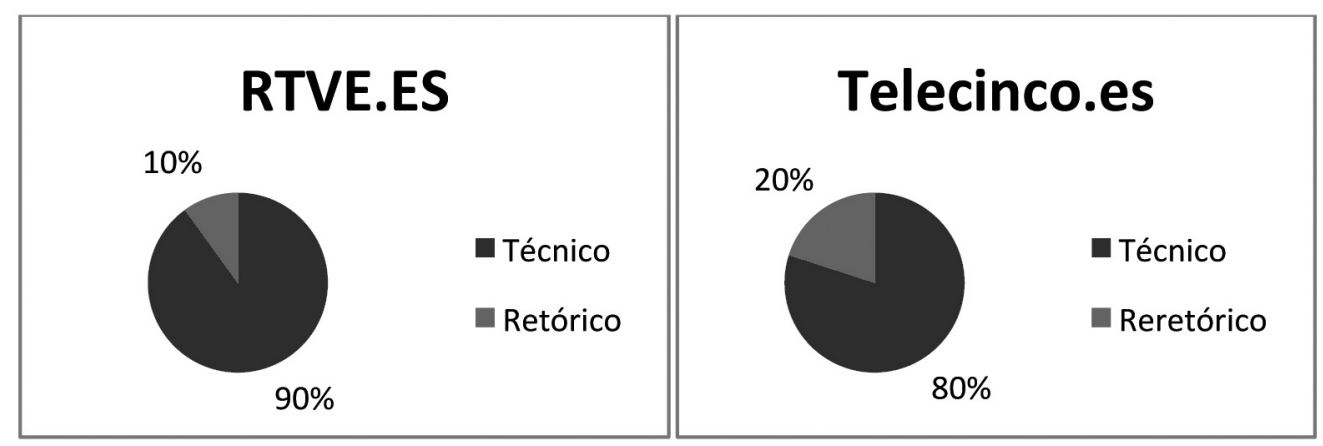

Fuente: elaboración propia 


\section{8. ¿El contenido de la pieza audiovisual es informativo o afectivo?}

El resultado obtenido en esta categoría corrobora una de nuestras hipótesis de partida, que era que el contenido de los vídeos encontrados en Telecinco.es serían más sensacionalistas que los de Rtve.es. Los resultados confirman esta hipótesis (tabla 9): el 80\% de los vídeos analizados de Rtve.es tienen un contenido informativo frente al $70 \%$ de los vídeos analizados en Telecinco.es que tienen un contenido más afectivo.

Tabla 6. Contenido audiovisual

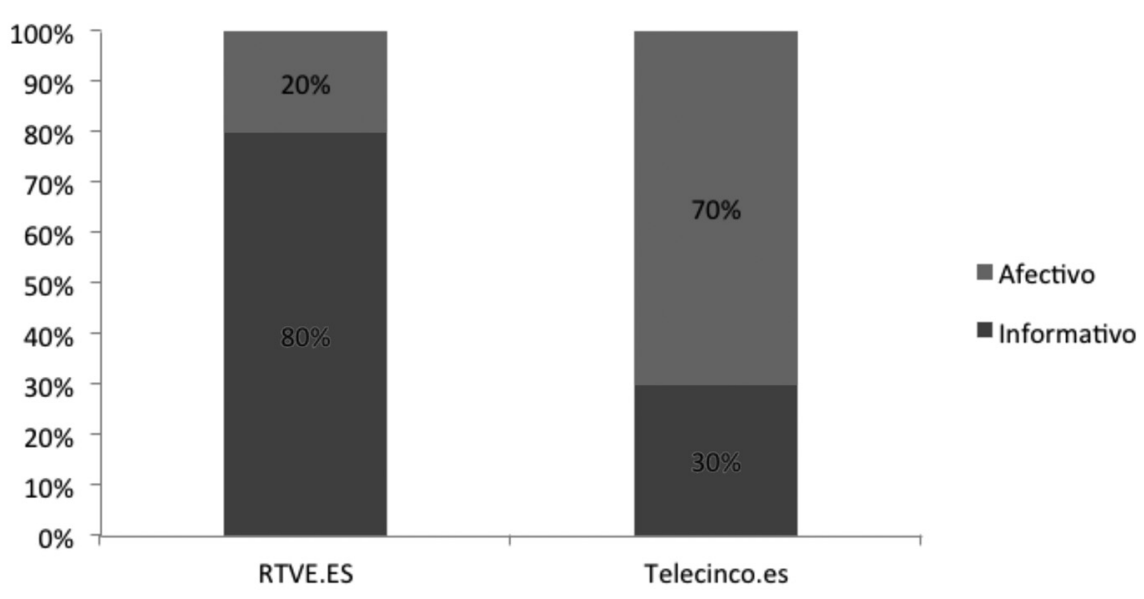

Fuente: elaboración propia.

\section{Conclusiones}

Tras el análisis descriptivo llevado a cabo de las websites de ambas cadenas de televisión y teniendo en cuenta las dificultades en el análisis de los vídeos que se cuelgan en Internet, se puede concluir que en ambas cadenas existe una tendencia a cubrir los sucesos tal y como se venía haciendo en la televisión tradicional. Sin embargo, aún se pueden percibir ciertas deficiencias en la elaboración de los vídeos, propias, seguramente, de variables como el número de profesionales que se encargan de elaborar estas piezas audiovisuales para la web ya que ante la crisis del sector las plantillas se han visto reducidas.

Partiendo de la función de servicio que debe tener una cadena de televisión pública, otorgar mayor cobertura a temas de interés social debería ser uno de los principales cometidos de estas televisiones. En este estudio Rtve.es durante el periodo de investigación alojó un mayor número de vídeos en su site, por encima de Telecinco.es, dando por tanto un mayor valor informativo al suceso que la cadena privada. 
En cuanto a la naturaleza del contenido publicado en ambas webs, Rtve.es ha llevado a cabo un tratamiento más informativo que Telecinco.es donde la mayor parte de las piezas audiovisuales analizadas encierran una mayor carga afectiva. Se trata de una realidad que responde a la naturaleza de la cadena privada y a los tipos de programa que emite en su parrilla.

A la hora de usar los diferentes géneros periodísticos en la construcción de piezas audiovisuales para la red, se puede comprobar que el reportaje y los directos son los preferidos para narrar sucesos. Además, en cuanto a los montajes y las ediciones de los vídeos no reflejan mucha complejidad, en algunos casos se podría decir que se tratan de piezas muy sencillas y con pocos recursos para planos, algo que en Internet se podría mejorar ya que el periodista dispone de más tiempo para montar y editar los vídeos, una vez que éstos han sido emitidos en los informativos de la cadena.

A pesar de las recomendaciones de los expertos en la materia, sobre cómo los medios deberían hablar de los individuos (víctimas y verdugos) que participan en un sucesos, en ambas cadenas hay una alta presencia de aquellos personajes que forman parte del entorno de los supuestos culpables. Un hecho que deja ver aun una falla a la hora de tratar acontecimientos de esta naturaleza relacionados con violencia juvenil y la violencia machista y que exige una mayor atención por parte de los medios. Se podría decir que este vicio heredado de los medios tradicionales se mantiene hoy en día en Internet.

\section{Referencias bibliográficas}

Barthes, R. (1962): " La estrucutura del suceso", en Ensayos Críticos. Barcelona: Seix Barral, pp. 225-236.

Bordieu, P. (1996): "Sur la télévision, suivi de L’eAIMC", en Marco General de los medios en España 2012. Madrid.

Bustamante, E. (2002): Comunicación y cultura en la era digital. Industrias, mercados y diversidad en España. Madrid: Gedisa.

Castells, M. (2005): La era de la información. La sociedad red (Vol. 1). Madrid: Alianza.

Cebrián Herreros, M. (2004): Modelos de televisión: generalista, temática y convergente con Internet. Barcelona: Paidós.

Díaz Arias, R. (2009). "El vídeo en el ciberespacio: usos y lenguaje”, Comunicar. Revista de Medios de Comunicación y Educación. Disponibe en: http://www.revistacomunicar.com/index.php?contenido=detalles\&numero=33\&articulo=332009-08

Díaz Fernández, N. (2003): La violencia Sexual y su representación en la prensa. Barcelona: Antrophos.

Edo, C. (2003): Periodismo informativo interpretativo. El impacto de Internet en la noticia, las fuentes y los géneros. Sevilla: Comunicación Social.

EGM. (2009). Audiencia en Internet. Febrero/Marzo 2009. Madrid: EGM. 
García-De-Torres, E. (2010). “Contenido generado por el usuario: aproximación al estado de la cuestión”, El Profesional de la Informacion, 19(6), 585-594. (doi:10.3145/epi.2010.nov.04).

Jenkins, H. (2006). Convergence culture: where old and new media collide. NY: U Press.

Kazez, R. (2009). "Los estudios de casos y el problema de la selección de la muestra. Aportes del Sistema de Matrices de datos", Subjetividad y Procesos Cognitivos, 13, pp. 71-89.

Mayoral, J. (2009): "A la búsqueda del impacto", Cuadernos de periodistas, vol 18, pp. 63-72.

Mazziotti, N. (2005): “Los géneros en la televisión pública”, en Rincón, O.: Televisión pública: del consumidor al ciudadano. Buenos Aires: La Crujía.

Muñiz, C., \& José, I. J. (2004): “Encuadres noticiosos e inmigración. Un análisis de contenido”, ZER, 9(16) pp. 87-104.

Palazio Arko, G. J. (2003): “Usabilidad, interacción y arquitectura en la televisión por Internet”, en López Vidales, N. \& Peñafiel Saiz, C.: Odisea 21: la evolución del sector audiovisual. Madrid: Fragua.

Puyal Sanz, A. (2008): “Los márgenes de la pantalla: efectos del vacío”, Área abierta, pp.1-14.

Rodríguez Fuentes, C. (2010). “Televisión en Internet”, Icono14, 8(1), 8-28.

Ruano López, S. (2008): “Internet: nuevo medio de difusión para los contenidos televisivos”, Hologramática , pp.55-64.

Salaverría, R. (2005): Cibermedios. El impacto de internet en los medios de comunicación en España. Sevilla: Comunicación Social.

Semetko, H. A., \& Valkenburg, P. M. (2000): "Framing European Politics: a content analysis of press and television news", Journal of Communication, pp. 93-109.

Sempere, P. (2007): Mc Luhan en la era de Google. Madrid: Popular.

Tourinho, C. (2009): Inovação no telejornaismo. O que você va ver a seguir. Brasil: Espaçolivros. 